\title{
Asian Children with Autism in US Schools: Potential Drivers of Unexpected Disproportionality
}

\author{
Denise R. Foley \\ Worcester State University, United States
}

\begin{abstract}
Racial and ethnic disparities in both the identification and treatment in special education in the US has been well-documented with Black and Hispanic students being at significantly greater risk for school-based identification of disabilities, in general, and certain disability types in particular, as compared to White counterparts. By contrast, Asian students are much less likely than Whites to be identified as having disabilities in all categories except one: autism. There is a lack of research into the reasons for the unexpectedly high rates of schoolbased autism identification of Asian students. An examination of data collected during the evaluations of three Indian children suggested at least two drivers. Examples of how these potential drivers manifested in these cases and implications for educators are provided.
\end{abstract}

\section{Introduction}

This paper sought to identify the potential sources of higher than expected rates of school-based autism identification in Asian students. In order to put the issue in context, in this section, we first examine the racial and ethnic diversity of the United States and it schools. Then, we review the diversity of students in US public schools, followed by an overview of how special education "works" and what it "looks like" at the national and state levels. We then describe disproportionality, focusing on how it manifests in both well-documented and unexpected ways in terms of racial and ethnic characteristics and in special education identification. We put special focus on autism and Asian children in the US schools. Finally, we discuss potential sources for unexpected disproportionality and how it manifested during the evaluations of three Indian children enrolled in a US school district.

\section{Literature Review}

\subsection{Diversity in the US}

The US Census is a demographic survey of all individuals living in the country including native and naturalized citizens, those on visas for work or study, as well as individuals who immigrate to the US for a variety of reasons. It is conducted every ten years. The most recent census was in 2010; the next will be 2020 . One of the questions asked on the survey is racial and ethnic identification.

The major categories individuals can describe themselves in terms single race include Asian, Black, Native American, Pacific Islander or White. Table 1 delineates which race individuals should classify themselves relative to region of origin. In terms of ethnicity, the U.S. Census Bureau classifies individuals as Hispanic/Latino or Not. Hispanic individuals may describe themselves as any race [1]. In 2000, for the first time, the Census provided options for individuals to describe themselves as more than one race.

Table 1. US Census: race and regions of origin

\begin{tabular}{|c|c|}
\hline Race/Ethnicity & Region of Origin \\
\hline White & $\begin{array}{l}\text { Europe } \\
\text { Middle East } \\
\text { North Africa }\end{array}$ \\
\hline Black & Africa \\
\hline $\begin{array}{l}\text { American Indian or } \\
\text { Alaska Native }\end{array}$ & $\begin{array}{l}\text { North American } \\
\text { South America } \\
\text { Central America }\end{array}$ \\
\hline Asian & $\begin{array}{l}\text { Far East } \\
\text { Southeast Asia } \\
\text { India }\end{array}$ \\
\hline $\begin{array}{l}\text { Native Hawaiian or } \\
\text { other Pacific } \\
\text { Islander }\end{array}$ & $\begin{array}{l}\text { Hawaii } \\
\text { Guam } \\
\text { Samoa } \\
\text { Pacific Islands }\end{array}$ \\
\hline
\end{tabular}

The richness of diversity in the United States is due in large part to immigration. Since 1965, the number of immigrants living in the U.S. has quadrupled. Currently, immigrants account for over $13 \%$ of the total population. According to one 2010 US Census Bureau report, the Asian population grew faster than any other population from 2000 to 2010 and accounts for approximately $5 \%$ of the entire population [1]. As shown in Figure 1, not only are Asian immigrants projected to surpass the number of Hispanic immigrants annually, but also Asians are projected to the largest immigrant group in the U.S. by 2055 . In 
2015 , the top country of origin for immigrants was India [2].

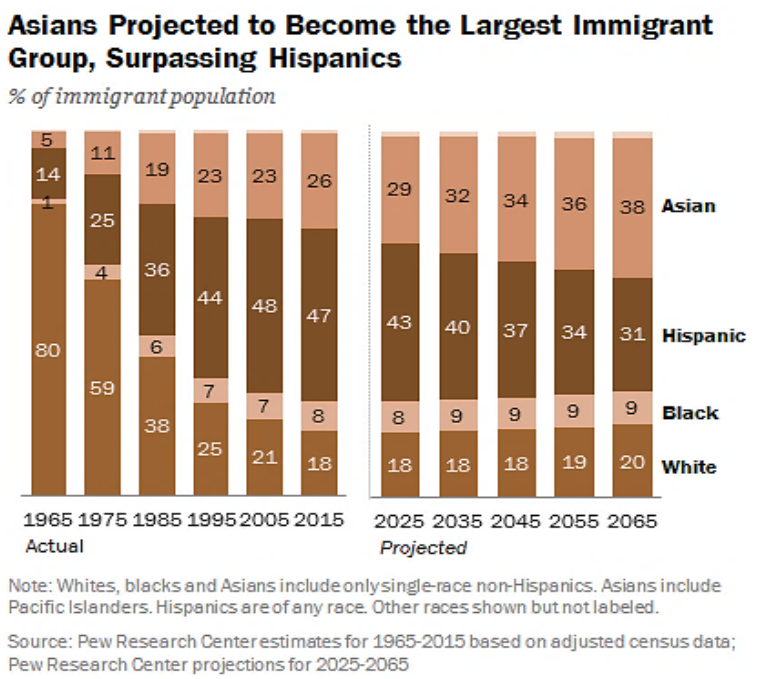

Figure 1. US Immigration: racial and ethnic trends Image from: www.pewresearch.org [2]

\subsection{Diversity in the US Schools}

There are over 50 million children enrolled in schools in the United States today. The vast majority of students are enrolled in publically funded schools. Figure 2 summarizes the enrollment of children ages 3 (preschool) through 19 (last year of high school) in US public schools from 2000 through 2015 with projections through 2027 [3].

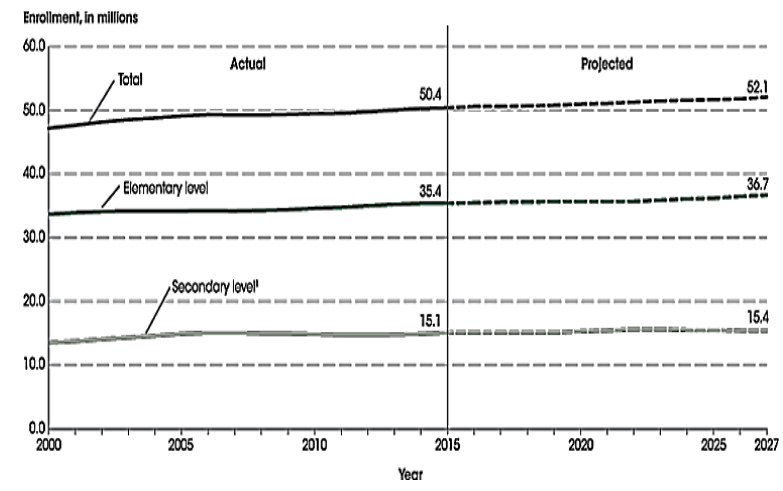

Figure 2. US public school enrollment: 2000-2016 with projections Image: www.nces.ed.gov [3]

In 2011, racial and ethnic minorities made up more than half of all children born in the US. In 2014, for the first time, white students made up less than 50 percent of students enrolled in elementary and secondary schools [4]. The trends and projections for the racial and ethnic diversity of children in US schools is depicted in Figure 3. [3]. While the diversity trend in the American school student population is increasing at greater than previously projected rates, the diversity of educators has remained stagnant: over $80 \%$ of teachers [5], over $80 \%$ of principals [6] and almost $90 \%$ of school psychologists are White [7].

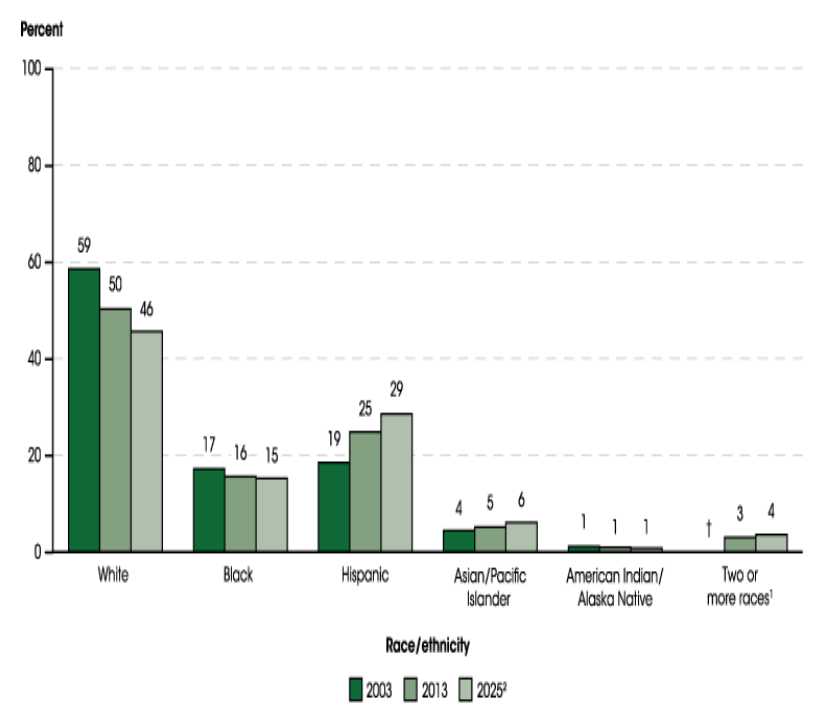

Figure 3. Racial and Ethnic Diversity Trends US School-Age Children Image: www.nces.ed.gov [3]

\subsection{Special Education in the US}

2.3.1. National Level. Prior to 1975 , when the federal law, The Education for All Handicapped Children Act ( $P L$ 94-142) was passed, there was no legal requirement to educate students with disabilities in US publically-funded schools. With the passage of this law, all children, adolescents and young adults with disabilities, aged 6 to 22 years, became entitled to a free, appropriate public education (FAPE), in the environment most similar to their peers (LRE), while receiving specially designed instruction and related services designed to meet their individual needs, as outlined in an Individualized Education Plan (IEP). This law set the minimum standards that all 50 states had to meet relative to the education of children and youth with disabilities in first grade through the age when their typically developing peers graduate from college.

In 1986, federal law 94-142, was amended to extend the rights outlined in the Act to children ages 3 to 6 years. This reflected the recognized need for special education services for children with disabilities in preschool and kindergarten, prior to when they enter first grade at the (typical) age of 6 .

In 1990, the federal law was reauthorized, revised and renamed as the Individuals with Disabilities Education Act (IDEA) reflecting a respectful, "person-first" mindset: that a disability is only one characteristic of a child/adolescent/young adult; it does not define them; that individuals have strengths and their individuality must be treated with dignity. Relevant to the purpose of this paper, it was not until 
this reauthorization that autism was determined to be one of the official categories under which an individual could qualify for special education services. IDEA, as the federal law became known, also added the category of traumatic brain injury in 1990.

In 1997, and again in 2004, the Federal law was reauthorized; however, the revision details are not relevant to the scope of this paper.

Though the law was officially renamed in 2004 to the Individuals with Disabilities Education Improvement Act (IDEIA), it is still referred to as IDEA at all levels of government and in the public schools. Depending on the scope of the revision, the federal government gives states time (typically two years) to revise their education regulations and procedures

2.3.2. Eligibility. It should be noted that while collaboration with professionals outside of the school (e.g., medical doctors, clinical psychologists) is welcome, a clinical diagnosis based on DSM-5 or ICD-10 criteria is not required for a child to be eligible for special education services. Neither does such a diagnosis result in automatic qualification. This is true for all disability categories, including autism. In other words, clinical diagnoses are neither required, nor sufficient to qualify for special education. Instead, in US schools, students must have one or more disabilities outlined in the IDEA and the disability must be "educationally handicapping." In other words, the student must not be making expected progress in the general curriculum as a direct result of this disability

2.3.3. State Level. States must meet the minimum standards set forth in federal law and may never be more restrictive; however, they may provide additional benefits. Massachusetts, where this study took place, is a state that goes beyond the minimums required by federal law. For example, the federal law stats that a child must require specially designed instruction by a special education teacher in order to be eligible for related services like speech therapy. Many states follow that standard. Massachusetts, by contrast, says that a student with a disability may be eligible for specially designed instruction $O R$ related services. Another example is the federal category of traumatic brain injury. Massachusetts renamed this category "neurological" and expanded eligibility to children with congenital or degenerative brain defects whereas the federal law expressly does not. Table 2 summarizes the thirteen disability categories defined by federal law under which a child may be determined to be eligible for special education services and their Massachusetts cognates.

During academic year 2015-16, the most current year available for in-depth national data, of the 50 million children attending US public schools, $13.8 \%$ received special education services under IDEA. The range of eligibility among the 50 states varied widely, from a low of $8.6 \%$ in Texas to a high of $17.5 \%$ in New York [8].

Table 2. Comparison of Federal and MA State disability categories

\begin{tabular}{|c|c|}
\hline Federal & Massachusetts \\
\hline Developmental Delay & Developmental Delay \\
\hline Autism & Autism \\
\hline $\begin{array}{l}\text { Deaf-Blindness, Deafness } \\
\text { Visual Impairment }\end{array}$ & $\begin{array}{l}\text { Sensory: Hearing, } \\
\text { Vision, Deaf-Blind }\end{array}$ \\
\hline Emotional Disturbance & Emotional Impairment \\
\hline Traumatic Brain Injury & Neurological \\
\hline Intellectual & Intellectual \\
\hline $\begin{array}{l}\text { Speech or Language } \\
\text { Impairment }\end{array}$ & Communication \\
\hline Orthopedic & Physical \\
\hline Other Health Impairment & Health \\
\hline Multiple disabilities & Multiple disabilities \\
\hline
\end{tabular}

The rate in Massachusetts, a perennially "top 3" state in terms of highest rates of children eligible for special education services, was $17.6 \%$.

\subsection{Disability Categories}

2.4.1 Rates. As shown in Figure 4 [3], in 2015-16, the broad category of Specific Learning Disability (encompassing all learning disorders of reading, written expression and mathematics), was the most common category under which students were eligible (38\%) for special education services across the US.

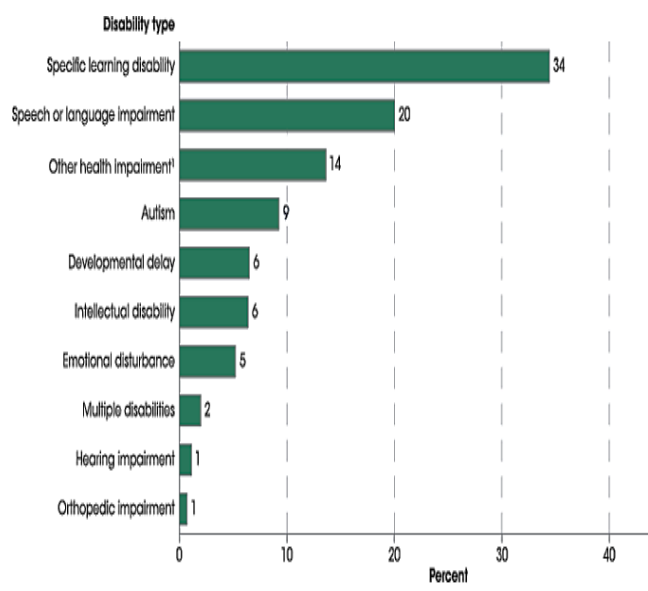

Figure 4. 2015-16 Rates of special education eligibility by disability category Image: www.nces.ed.gov [3] 
This was followed by the categories of speech and language impairments $(20 \%)$ and $(9 \%)$ other health impairment - the category under which Attention Deficit Hyperactivity Disorder is classified. Nationwide, these three categories describe $70 \%$ or more of the students serviced under IDEA and thus, are referred to as "high incidence" disabilities. The rank and percentages of these three "high incidence" disability categories have remained stable for many years at both the national level and for all states, including Massachusetts.

2.4.2 Disproportionality. Disproportionality refers to the over- or under-representation of a particular demographic group in certain programs relative to the group's presence in the general population. The phenomenon of disproportionality in American schools is both long-standing and well-documented. Numerous studies have highlighted the overidentification of economically-disadvantaged, culturally and linguistically (CLD), and racially and ethnically diverse students, particularly Black and Hispanic students, as "disabled" as compared to their White and Asian peers [9]. Figures 5 and 6 summarize the most current information regarding the disproportional representation of racial and ethnically diverse students at both the national level and in Massachusetts.

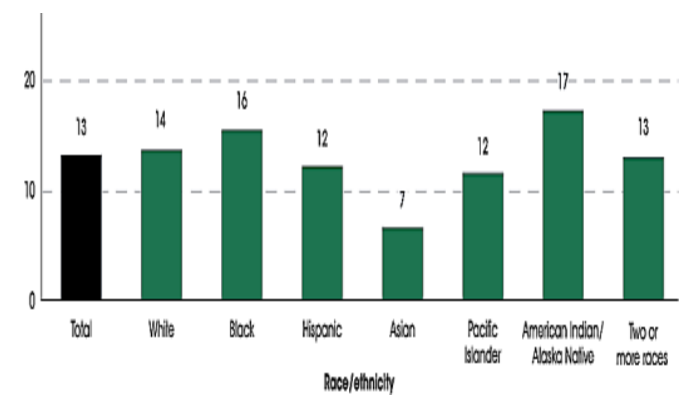

Figure 5. Percentages of Students served under IDEA ages 3-21, by race and ethnicity, 2015-16 Image: www.nces.ed.gov [3]

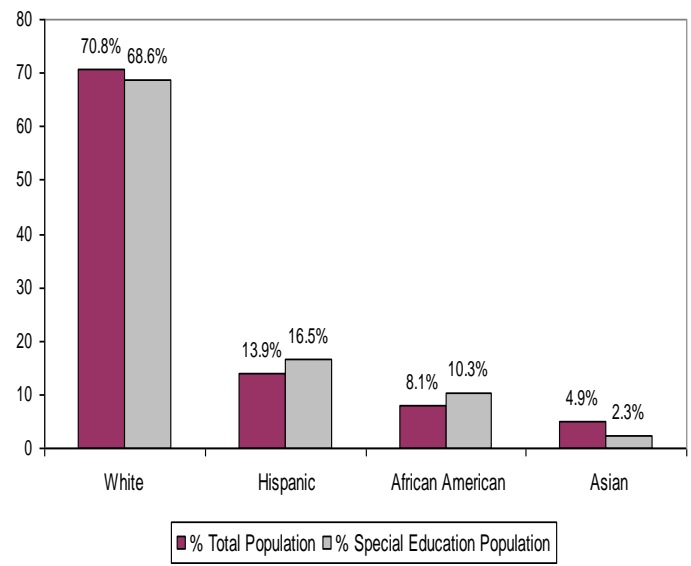

Figure 6. Massachusetts Comparison of Total vs. Special Education percentages, by race and ethnicity Image: www.doe.mass.edu [10]
Perhaps the powerful impact of disproportionality is best conveyed by "Risk Ratios." These ratios represent the "risk" that a racial and/or ethnically diverse child will be determined to have disability in US schools as compared to their White counterparts. Though ratios vary widely by state at the national level, on average, as compared to their White counterpart, any Black child in the U.S. is 1.5 times more likely to be labelled as having a learning disability, twice as likely for emotional disability and 2.5 times more likely for intellectual impairment [11].

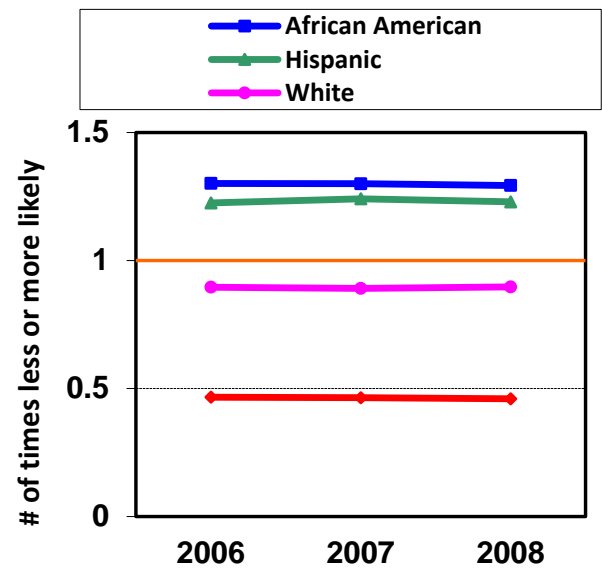

Figure 7. Likelihood that a student is found eligible for Special Education in MA by Race and Ethnicity Image: doe.mass.edu [10]

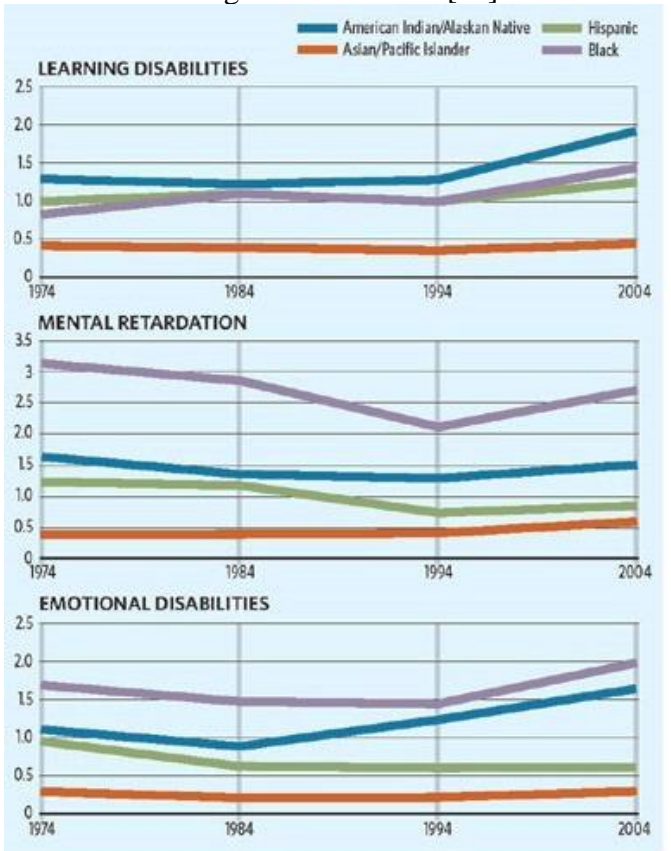

Figure 8. Nationwide Risk of Identification by Category and Race as Compared to White Children Source: Sullivan, et al. 2009 [9]

Figures 7 and 8 illustrate both historical trends and the most recent risk by race ratios calculated for the selected vulnerable racial and ethnic groups, as well as, the types of disabilities children are most to be 
diagnosed with in schools in Massachusetts, as well as nationally.

Though included in reports of risk/race ratios, the other end of the disproportionality spectrum (underrepresentation in special education) is where most Asian children may be found, suggested that they are often overlooked and under-served [12]. With one exception, at both the national and state levels (e.g., California, Asian students are MUCH (at least $50 \%$ ) less likely than White students to be labeled as having any type of disability. The exception is Autism.

2.4.3. Autism: Prevalence and Racial/Ethnic Disparities. As defined in the DSM-5, Autism Spectrum Disorder (ASD) is a neurodevelopmental disorder characterized by persistent deficits in social communication and social interaction and restrictive, repetitive patterns of behavior, interests or activities present in since early development, causing clinically significant impairment in social, occupational or other important areas of functioning [13, p.50]. As conceptualized in the DSM-5, ASD encompasses disorders that had been previously distinct diagnoses including, autistic disorder, Asperger's Disorder, Rett's Disorder, childhood disintegrative disorder and pervasive developmental disorder not otherwise specified [13, p. 809].

Though at the federal level autism is categorized as a low incidence disability, the number of children diagnosed with ASD in the US has increased dramatically over the past 15 years: from 1 in 166 births in 2004, to less than 1 in 59 births in 2018 [14]. A recent study of the relative risk of autism identification across the US found Black and Hispanic students less likely than White children to be diagnosed with autism, while Asian children were 1.2 times more likely to be diagnosed with autism [15]. The question of "why" this is the case has not yet been answered and was the impetus for this paper.

\section{Problem Statement and Study Purpose}

Though ASD is the one of the most widespread neurodevelopmental disorders with rapidly increasing incidence rates and the racial and ethnic disparities in special education identification and services, including autism, are well-documented, there is limited research investigating multicultural factors and ASD [16]. This seems especially true relative to the unexpectedly high rates of autism identification in Asian children in US schools.

The purpose of this paper was to describe potential reasons why Asian children, who in general, at much lower risk that any other racial/ethnic group of children in the U.S. to be determined to have an educationally handicapping condition are determined eligible under the autism category than their eligible at a much higher much more eligible for special education.

\section{Methodology}

\subsection{Participants}

The sample was one of convenience. Three Asian Indian children, all male, were referred for initial special education evaluations by their teachers due to concerns about potential autism, especially social communication skills, during academic years 2016-17 and 2017-18. What follows are broad descriptions of the boys (all pseudonyms) including key demographics.

- Dhruv was age 8 and in $3^{\text {rd }}$ grade. Hindi was his primary language as well as that if his parents. Though some English was spoken in the home, upon enrolling in the district, he was determined require English Language Learner services. He had immigrated to the US with his parent less than one year and had attended school for less than six months (due to summer break) prior to his referral for a special education evaluation.

- Ishank was age 9 and in $3^{\text {rd }}$ grade. Marathi was the primary language of the home, however both he and his parents also English, primarily outside the home. Ishank was born in India and immigrant to US at age 2 .

He had recently moved into the town/school but had made satisfactory progress in his previous Massachusetts school district for grades K,1 and 2 which had far fewer Asian Indians.

- Kumar was age 10 and in $4^{\text {th }}$ grade. English was his primary language, though Hindi was the primary language of his home. He was born in the U.S. and had only attended school in the district

\subsection{Setting}

These students attended elementary and intermediate public schools in a high-performing suburban district in Massachusetts whose population is more diverse and more affluent than state and national averages. The characteristics of the students and teachers in the district as compared to state average and national averages are summarized in Table 3. In addition to Hindi and Maratha, Telugu, Gujarati and Urdu were among other Indian languages spoken in the homes of the children in the district. 
Table 3. Key Characteristics: District, State, National Percentages 2018

\begin{tabular}{|c|c|c|c|}
\hline Students & District & State & US \\
\hline Asian & 32.6 & 6.9 & 5.5 \\
\hline Black & 1.9 & 9.0 & 15.7 \\
\hline Hispanic & 5.8 & 20.0 & 27.1 \\
\hline White & 56.6 & 60.0 & 47.7 \\
\hline Native American & 0.1 & 0.2 & 1.0 \\
\hline $\begin{array}{l}\text { Nat. Hawaiian, } \\
\text { Pac.sl. }\end{array}$ & 0.1 & 0.1 & 1.0 \\
\hline $\begin{array}{l}\text { Multi-Race, } \\
\text { Non-Hispanic }\end{array}$ & 3.0 & 3.6 & 3.1 \\
\hline $\begin{array}{l}\text { First Language } \\
\text { Not English }\end{array}$ & 25.6 & 20.9 & -- \\
\hline $\begin{array}{l}\text { English Language } \\
\text { Learners }\end{array}$ & 9.5 & 10.2 & 9.5 \\
\hline $\begin{array}{l}\text { Students with } \\
\text { Disabilities }\end{array}$ & 15.0 & 17.7 & 13.2 \\
\hline $\begin{array}{l}\text { Economically } \\
\text { Disadvantaged }\end{array}$ & 8.7 & 32.0 & 19.1 \\
\hline \multicolumn{4}{|l|}{ Teachers } \\
\hline White & 96.1 & 89.9 & 82.0 \\
\hline Asian & 2.4 & 1.5 & 2.0 \\
\hline Hispanic & $<0.01$ & 4.2 & 9.0 \\
\hline $\begin{array}{l}\text { Median Household } \\
\text { Income (2015) }\end{array}$ & $\$ 100,552$ & $\$ 70,628$ & $\$ 55,775$ \\
\hline
\end{tabular}

\subsection{Procedures}

Developmental histories, interviews with parents and teachers, multiple observations of the children across structured and unstructured settings, cognitive and select neurocognitive processing tests were administered. Broad rating scales of social, emotional, behavioral and adaptive functioning, as well as, those rating scales designed to assist in the identification of autism were administered. Test results are not the focus of this paper; the "story" is not in the scores. Rather, the potential drivers of disproportionality were found during the process of reviewing and reflecting upon the evaluation process, the interviews with parents and teachers, and especially in the written comments made by parents and conversation with children.

\section{Findings}

\subsection{Evaluation Procedures and Tools}

Results of these cases suggested that the format, normative samples, content and diagnostic criteria of the major tools and procedures used to assess autism may contribute to over-identification of Asian Indians in the US.

5.1.1 Format. The assessment of autism in children is conducted through observation, rating scales completed by and structured interviews with parents, guardians, caretakers and teachers of children. Lau and Blatchley [17] remind us that in general, standardized interview protocols are designed for "individuals who are well assimilated into the dominant culture of [the U.S.] and are characterized by a laundry list of direct questions (p. 147)," which may not only seem intrusive and rude, but also, potentially confusing.

5.1.2 Normative Samples. The "representativeness" of a test or rating scale is determined via comparison of the demographic characteristics of the normative sample relative to findings of the U.S. Census regarding the general population, from infancy through adulthood and old age. The rating scales used in the assessment of school aged children, including those suspected to have or have been diagnosed with autism (e.g., GASR-3, BASC-3, SRS-2) use the 2010 US Census data to determine the representativeness of their normative sample $[18,19]$. However, at least two popular rating scales measuring autism (CARS-2, ASRS) use the 2000 US census for their normative comparisons [20, 21].

To date, there are no known valid and reliable published measures of social, emotional, behavior or adaptive functioning, much less autism, with Asian Americans as its normative group. This, plus the backdrop of the increasing diversity of the school-age population, one might argue that even when using the 2010 US Census results, the normative samples of tools used to aid in autism diagnosis, are not representative of the children in US schools of today or tomorrow, the very population they are designed to fairly assess. That argument, however, is beyond the scope of this paper.

5.1.3. Concepts and Constructs. The semistructured observation protocol, often described as the "gold standard" in autism diagnosis [22], and the most commonly used rating scales used to identify autism and symptom severity were developed and normed in the U.S. Further these tools are either somewhat or directly aligned with DSM-5 diagnostic criteria for autism, or its predecessor, the DSM-IV TR: both developed and published in the US. As such, the conceptualization of what are "appropriate" and "typical" thoughts, feelings and behaviors of children, reflect mainstream U.S (Western, Anglo-European) norms and values - not necessarily those of immigrant or first generation Asian Americans with different levels of acculturation from a broad array of cultural backgrounds. 
Reflecting the changing demographics in the US, in addition to measures of adaptive skills and autism, several measures of cognition, academic achievement, have been translated into Spanish. As of this writing, it appears that neither the structured observation protocol nor any rating scales most commonly used to assess for adaptive behaviors and symptoms of autism have been translated into any of the national languages of India [23].

Translations into native language or the use of interpreters so that items for the translated measure are similar in meaning to items from the original measure do not eliminate culture bias because they reflect the values and beliefs of the culture in which they were developed--in many cases, the US.

5.1.4 The DSM-5 and Culture. The DSM-5 includes a "Cultural Formulation" section designed to increase the effectiveness of diagnostic assessments and clinical management by reminding practitioners that the experience of "illness" must be understood within its cultural context. The section describes the constructs of culture, race and ethnicity, as well as, a semi-structured interview (the Cultural Formulation Interview, CFI) designed to assess the "impact of culture on aspects on an individual's clinical presentation and care $[13$, p.750]."

Relative to the interaction between culture and the diagnostic criteria of mental disorders, the DSM-5 reminds us that:

- Very few cultural concepts correspondence directly to a single DSM-5 diagnosis.

- Variants of a single DSM-5 clinical term may be considered distinct concepts depending upon cultural context

- Cultural concepts may apply to a wide range of presentation and severity: from significant pathology to not meeting the criteria for any DSM-5 mental disorder.

- The same term (e.g., "depression") can refer to a range of cultural conceptions, from idioms of distress, to syndromes, or even perceived etiology [13, p.758].

The DSM-5 further reminds us that while there are different expectations for social interaction, nonverbal behavior and relationships, the diagnosis of autism should reflect marked impairment relative to the cultural norms for these domains. Given the racial and ethnic disparities in autism diagnoses, it is surprising to find that the only culturally related diagnostic issue raised for autism, was the potential for late or underdiagnosis of African American children in the US [13, p.15].

\subsubsection{Case Sample Manifestations}

\section{Poor Social Cmmunication or Acculturation?}

One example of the different cultural interpretations of social communication skills was Dhruv's teachers' concerns about his limited, fleeting eye contact with adults, limited spontaneous speech production, preference for one friend, lack of asking questions in class and waiting for direct instructions from his teacher before acting (characterized as "dependence"). Though what might have seemed to be a reflection of DSM-5 criteria to his teacher, Dhruv's behavior was quite normal given his background. He was a native Hindi speaker with limited English spoken in his newly immigrated family. He had less than six months experience in a US public school and this was his second teacher within that time frame (due to two months of summer break and changes in grade level).

\section{Highly Fixated or Normal Interest?}

The differences between teacher and parent attitudes towards Ishank's knowledge of the statistics of a major league baseball team highlight the role of cultural context in applying the second DSM-5 diagnostic criteria: restricted, repetitive patterns of behavior, interests or activities. In contrast to his teachers who were concerned about his "number fixation," his mother described Ishank as very curious. She said when he was interested in something, he focused on it and that his [then current] interest was that baseball team. Consistent with not only cultural expectations for high achievement but also Ishank's actual (high) math achievement, his mother considered his knowledge of the statistics of the team and team members to be a reflection of strong math aptitude.

\section{Inflexible and Rigid or Independent and Pragmatic?}

In a similar vein, home and school views of Ishank's unwillingness to follow some directions (e.g., explain in writing how he arrived at a math answer--a requirement on state mandated testing) differed widely. While his teachers described him as frequently inflexible, often ignoring or refusing to follow directions, his mother described him as being "very go with the flow" at home. However, she also noted, that if he feels something is "unnecessary, he does not do it" and that this was considered acceptable/permissible behavior. 


\subsection{Languages, Variations and Attitudes}

5.2.1 Languages of India. While Hindi and English are the languages within which the central government must conduct official business, there is no one "national" language in India. By most accounts, there are eighteen national languages and over one thousand dialects spoken in India [24,25]. Though Hindi is the most common language in the country, only $42 \%$ of Indians speak it. Given its origins as an imposed, foreign language, there has been ambivalence and sometimes string animosity towards English in India. Nevertheless, English is considered by many to be the lingua franca in India.

The diversity of Indian languages and associated variety of spoken and written English were seen in both the children described in this paper and their parents. All the children spoke English in their classrooms. Their parents indicated that while English is "sometimes" or "often" used in the home, the primary Indian language was "always" spoken at home.

5.2.2 Language Variations. Dialects are broad categories of variations vocabulary and grammar of a language that are regionally based. Accents are variations in speech sounds, prosody (intonation, stress, rhythm), rate and fluency of a spoken language. Recognizing that it is not a monolith, single entity due to the many variations associated with regional dialects, whether one is a native speaker, immigrant, first- or second- generation immigrant, etc., language experts describe the unique sounds of "Indian English" or the "Indian Accent." Researchers [24, 25] have highlighted the unique elements of Indian English including:

- pronunciation of some vowel sounds (tell and take pronounced the same

- a pronunciation of some nd consonant sounds (wine and vine, they and day pronounced the same);

- use of verbs and verb tenses (Maya thought that she will eat. I called up Krish.)

- $\quad$ insertion, deletion or changes in word forms (Where is book? I want to share a good news; dreamt instead of dreamed)

- order of words in a sentence (At nine o'clock, I go to sleep)

- how questions are asked (What you are doing?)

\subsubsection{Language Attitudes and Bias}

Everyone has an accent. Affinity for familiar accents actually begins before birth [26]. The affective, behavioral and or cognitive reactions of listeners to language variations has been termed "language attitudes [27]" among other monikers.
Numerous sociological and linguistic studies have compared listener perceptions of English variations. Across different countries, settings and industries (including education), British English is consistently ranked as the most correct and prestigious variation, followed by Standard American English. These both rank above or well above Indian English [e.g., 28].

Beyond attitudes towards language variations, researchers have shown that it only takes just seconds or less for listeners to make judgements about a speaker's, character, social status, trustworthiness, and intelligence, oftentimes without awareness [28]. These implicit biases can have obvious far-reaching repercussions for individuals who speak with nonpreferred or even socially stigmatized accents.

While language attitudes and biases are held at an individual level, mass media can shape and perpetuate attitudes towards certain language variations [27]. Relative to Indian English, the most obvious example is "Apu," the grocery store clerk on the long running on the television show, The Simpsons. The portrayal of the character is considered by most to be very offensive, as it perpetuates negative stereotypes of Indians and mocks Indian English.

\subsubsection{Case Sample Manifestations}

Given their linguistic and cultural contexts, each boy demonstrated expected characteristics in their spoken English:

\section{Dhruv:}

- In response a question about who he lives with he asked, "How many people am I having in my family?"

- During pretend play with Legos, he said "I'm gonna make this a police"

- In response to seeing some candy in the office, he asked: "Wait, why is the candies here?"

Kumar:

- Regarding a math calculation problem on an achievement test, he asked, "On this one, can I do borrowing on here?"

Ishank

- During conversation, he stated, "I am wanting book."

It is certainly possible that unconscious, negative linguistic bias towards the English spoken by these children and their parents played at least some role in their White, mono-lingual teachers' request for special education evaluations of these children with expressed concerns about their social language and learning abilities and whether they might have autism. 


\section{Conclusion and Next Steps}

An examination of three cases of Indian children referred for initial evaluations with specific concerns about autism suggested two drivers underlying the unexpectedly high rate of Asian children qualifying for special education services under the category of autism in US Schools: a lack of culturally valid tools and implicit linguistic bias. While these two do not comprise an exhaustive list and they highlight issues that extend far beyond school district in which this study took place, they do provide some direction.

First, school-based personnel (e.g., school psychologists) can conduct ecologically based, culturally responsive evaluations that only incorporate published tools used to help diagnose with great caution (if at all). They must do more than seek translators. They must learn the symbolism, metaphors, associations and conceptualizations, beliefs and values of their Indian families, especially as relates to mental health, and social, emotional, behavioral and adaptive functioning.

Second, educators should learn about India and the rich and varied backgrounds and cultural contexts of the immigrant, first and second-generation Indians in their cities, towns and schools from Asian Indians, versus, for example, a quick online primer. There is no substitution for real-time, respectful conversation. They must learn about the educational (public and private) systems of India (a critical component to validating Ikshan's evaluation results).

Third, all educators (from principals to teacher assistants) should critically examine the cultural lenses through which they view the parents and students in their schools as both members of various groups, and as individuals. Relatedly, educators must not only acknowledge that we all have biases, but must also examine their own implicit and explicit biases, including those they hold towards Indian English.

Finally, educators should seek explicit instruction about not only about second language acquisition and stages of acculturation, but also about the variations which comprise "Indian English" such that these expected differences are not perceived as deficiencies.

\section{Limitations}

The initials findings summarized in this paper are not generalizable beyond the children and district discussed herein. The children were not a representative sample of all Indian children in the district. This high-performing district located in a high SES town with a very high Indian population is not representative of the state or the United States.

\section{References}

[1] US Census Bureau (2017) Race and Ethnicity. Retrieved https://www.census.gov/mso/www/training/pdf/raceethnicity-onepager.pdf.

[2] López, G. \& Bialik (2017). Key findings about U.S. immigrants. Washington, DC: Pew Research Center (May 3. 2017). Retrieved from: http://pewrsr.ch/2qz2zvx.

[3] Musu-Gillette, L., Robinson, J., McFarland, J., KewalRamani, A., Zhang, A., and Wilkinson-Flicker, S. (2016). Status and Trends in the Education of Racial and Ethnic Groups 2016 (NCES 2016-007). U.S. Department of Education, National Center for Education Statistics. Washington, DC. http://nces.ed.gov/pubsearch.

[4] National Center for Education Statistics, NCES (2016): National Elementary and Secondary Enrollment by Race/Ethnicity Projection Model, 1972 through 2026. Washington, DC: USDOE. Retrieved from https://nces.ed.gov/programs/digest/d16/tables/dt16_203.5 0.asp.

[5] Geiger, A. (2018). America's public school teachers are far less racially and ethnically diverse than their students. Fact Tank: News in the Numbers (8.2722018). Washington, DC: Pew Research Center, Retrieved from https://www.pewresearch.org/fact-tank/2018/08/27/ americas-public-school-teachers-are-far-less-racially-andethnically-diverse-than-their-students/.

[6] U.S. Department of Education (2016). The state of racial diversity in the educator workforce. Washington, D.C.: U.S.DOE, Office of Planning, Evaluation and Policy Development, Policy and Program Studies Service. https://www2.ed.gov/rschstat/eval/highered/racialdiversity/state-racial-diversity-workforce.pdf.

[7] Walcott, C.M., Charvat, J. McNamara, K.M. \& Hyson, D.M. (2016). School Psychology at a Glance: 2015 Member Survey Results. Bethesda, MD: National Association of School Psychologists. Retrieved from: https://www.nasponline.org/.../Membership\%20Survey\%2 02015\%20Handout.pdf

[8] McFarland, J., Hussar, B., Wang, X., Zhang, J., Wang, K., Rathbun, A., Barmer, A., Forrest Cataldi, E., and Bullock Mann, F. (2018). The Condition of Education 2018 (NCES 2018-144). U.S. Department of Education. Washington, DC: National Center for Education Statistics. Retrieved from https://nces.ed.gov/pubsearch/pubsinfo. asp?pubid=2018144

[9] Sullivan, A.L., A'Vant, E., Baker,J., Chandler, D., Graves, S., McKinney, E., \& Sayles, T (2009). Confronting inequity in special education, part I: Understanding the problem of disproportionality. Communiqué, 38 (1). Retrieved from: http://www.nasponline.org/publications/ periodicals/communique/issues/volume-38-issue1/confronting-inequity-in-special-education-part-iunderstanding-the-problem-of-disproportionality.

[10] Denninger, M. (2008). Disproportionality: A Look at Special Education and Race in the Commonwealth. Malden, 
MA: Massachusetts Department of Elementary \& Secondary Education. Retrieved from: https://files.eric.ed.gov/fulltext/ED508412.pdf.

[11] .S. Department of Education (2016). Racial and ethnic disparities in special education: A multi-year disproportionality analysis by state, analysis category, and race/ethnicity. Washington, D.C.: U.S.DOE, Office of Special Education and Rehabilitative Services.

[12] Pathappilil, J., Bhatt, H., \& Kabler, B. (2013). South Asian families' access to special education and mental health services: Obstacles and strategies. Communiqué, 41(7). Retrieved from: http://www.nasponline.org/ publications/periodicals/communique/issues/volume-41issue-7/south-asian-families-access-to-special-educationand-mental-health-services.

[13] American Psychiatric Association: Diagnostic and Statistical Manual of Mental Disorders, Fifth Edition. Arlington, VA: American Psychiatric Association, 2013.

[14] Autism Speaks. (2018). CDC increases estimate of autism's prevalence by 15 percent, to 1 in 59 children.

(April 26, 2018). Retrieved from https://www.autismspeaks.org/science-news/cdc-increasesestimate-autisms-prevalence-15-percent-1-59-children.

[15] Sullivan, A.L. (2013) School Based Autism Identification: Prevalence, Racial Disparities and Systematic Correlates. School Psychology Review, 42(3), 298-316.

[16] Nowell, K.P., Brewton, CM., Allain, E., \& Mire, AA. (2015). The influence of demographic factors on the identification of autism spectrum disorder: a review and call for research. Journal of Autism and Developmental Disorders, 2, 300-309. doi: 10.1007/s40489-015-0053-x.

[17] Lau, M.Y. \& Blatchley, L.A. (2009). A comprehensive, multidimensional, approach to assessment of culturally and linguistically diverse students. In The Psychology of Multiculturalism: A primer for practice, training and research, Jones, J.M. (Ed), pp. 139-171.

[18] Gilliam, J.E. (2014). Gilliam Autism Rating Scale, Third Edition (GARS-3) Examiner's Manual. Austin, TX: Pro-Ed, Inc.

[19] Constantino, J.N. \& Gruber, C.P. (2012) Social Responsiveness Scale, Second Edition (SRS-2) [Manual]. Torrance, CA: Western Psychological Services.

[20] Goldstein, S. \& Naglieri, J.A. (2010) Autism Spectrum Rating Scales (ASRS) [Manual]. North Tonawanda, NY: Multi-Health System, Inc.

[21] Schopler E, Van Bourgondien ME, Wellman, GJ, Love SR (2010). Child Autism Rating Scale, Second Edition (CARS-2). Torrance, CA: Western Psychological Services.

[22] Lord, C., Rutter, M. DiLavire, P.C., Risi, S., Gotham, K.,Bishop, S. (2012) Autism Diagnostic Observation Schedule, Second Edition (ADOS-2)[Manual; Modules 14]. Torrance, CA: Western Psychological Services.
[23] WPS Titles in Commercial Translation. Retrieved from: https://www.wpspublish.com/app/OtherServices/ PublishedTranslations.aspx.

[24] Faroqi-Shah, Y. (2012). Linguistic and Sociocultural Diversity Among South Asians. In Perspectives on Communication Disorders and Sciences in Culturally And Linguistically Diverse (CLD) Populations. Retrieved from: https://pubs.asha.org/doi/10.1044/cds17.1.6 https://pubs.asha.org/doi/10.1044/cds19.1.6.

[25] Shah, A. (2012) Accent Modification for Speakers with Indian Accents: Speech Characteristics and an Assessment Framework. In Perspectives on Communication Disorders and Sciences in Culturally And Linguistically Diverse (CLD) Populations. Retrieved from: https://pubs.asha.org/doi/full/10.1044/cds19.1.12

[26] Hogenboom, M. (9 March 2018). What does your accent say about you? BBC Future. Retrieved from: http://www.bbc.com/future/story/20180307-what-doesyour-accent-say-about-you.

[27] Bayley, R. \& Villarreal, D. (2018) Cultural Attitudes towards Language Variation and Dialects. In The TESOL: Encyclopedia of English Language Teaching (J.I. Liontas, Ed.) Hoboken, NJ: John Wiley \& Sons, Inc. DOI: 10.1002/9781118784235.eelt0297.

[28] Luu, C. (23 May 2017). Does your accent make you sound smarter? BBC Capital. London: British Broadcasting Company. Retrieved from http://www.bbc.com/ capital/story/20170523-does-your-accent-make-yousound-smarter. 